\title{
Visões da "insuficiência": \\ o nordeste e o desenvolvimento regional no pensamento social brasileiro ${ }^{1}$
}

\author{
André Luiz de Miranda Martins ${ }^{2}$
}

\begin{abstract}
Resumo
O presente artigo tem por objetivo localizar, na trilha do pensamento social brasileiro-nordestino (aqui representado por Gilberto Freyre, Josué de Castro e Celso Furtado) as concepções da Região Nordeste como pobre, "região-problema", "região explosiva". As concepções dos pensadores mencionados, expressas em obras selecionadas de sua autoria e de comentadores, foram apresentadas na ordem de sua menção, com cada uma delas correspondendo a uma seção específica: o Nordeste adocicado pela tradição e salgado pela modernidade, de Freyre; o Nordeste "barril de pólvora", em Castro; e o Nordeste como periferia e "região-problema", em Furtado. A ordem dessa apresentação é reveladora da forma como germinou, na intelectualidade nordestina brasileira, a ideia segundo a qual a pobreza, tão caracteristicamente nordestina, só seria combatida se tal empreitada fosse levada adiante sob a forma de intervenção estatal corretiva.
\end{abstract}

\section{Palavras-chave}

Região, Nordeste, Gilberto Freyre, Josué de Castro, Celso Furtado.

Recebido em 13 de outubro de 2009

Aprovado em 13 de maio de 2010

1 Versão modificada de comunicação apresentada no IX Congresso da Brazilian Studies Association - BRASA (Tulane University, Nova Orleans, março de 2008). O autor agradece a Raquel Lindôso, pelo apoio incondicional, e a Aristides Monteiro e Glaudionor Barbosa, pelas sugestões de bibliografia.

2 Economista. Doutor em Economia Aplicada pela Universidade Estadual de Campinas. Professor Adjunto do Centro Acadêmico do Agreste da Universidade Federal de Pernambuco - UFPE. 


\title{
Conceptions of Weakness: \\ The Brazilian Northeast and Regional \\ Development in Brazilian National Tought
}

\author{
André Luiz de Miranda Martins
}

\section{Abstract}

The following article aims to identify, in the path of the Brazilian National Thought (here represented by Gilberto Freyre, Josué de Castro e Celso Furtado), the conceptions of Northeastern Brazil as a poor, problematic, and even "explosive" region. The conceptions of those Brazilian national thinkers - expressed in their work as much as in some of their commentators -, were presented as they are mentioned it the text, with each thinker corresponding to a section: Freyre's Brazilian Northeast, sweetened by tradition and salted by modernity; Castro's "explosive" Northeast; and the Brazilian Northeast as peripheral and "problematic", according to Furtado. Such order of authors reveals the ways by which some Northeastern Brazilian intellectuals made germinate the idea of a characteristically Northeastern pattern of poverty, to be fought only in the presence of state intervention.

\section{Keywords}

Region, Brazilian Northeast, Gilberto Freyre, Josué de Castro, Celso Furtado. 


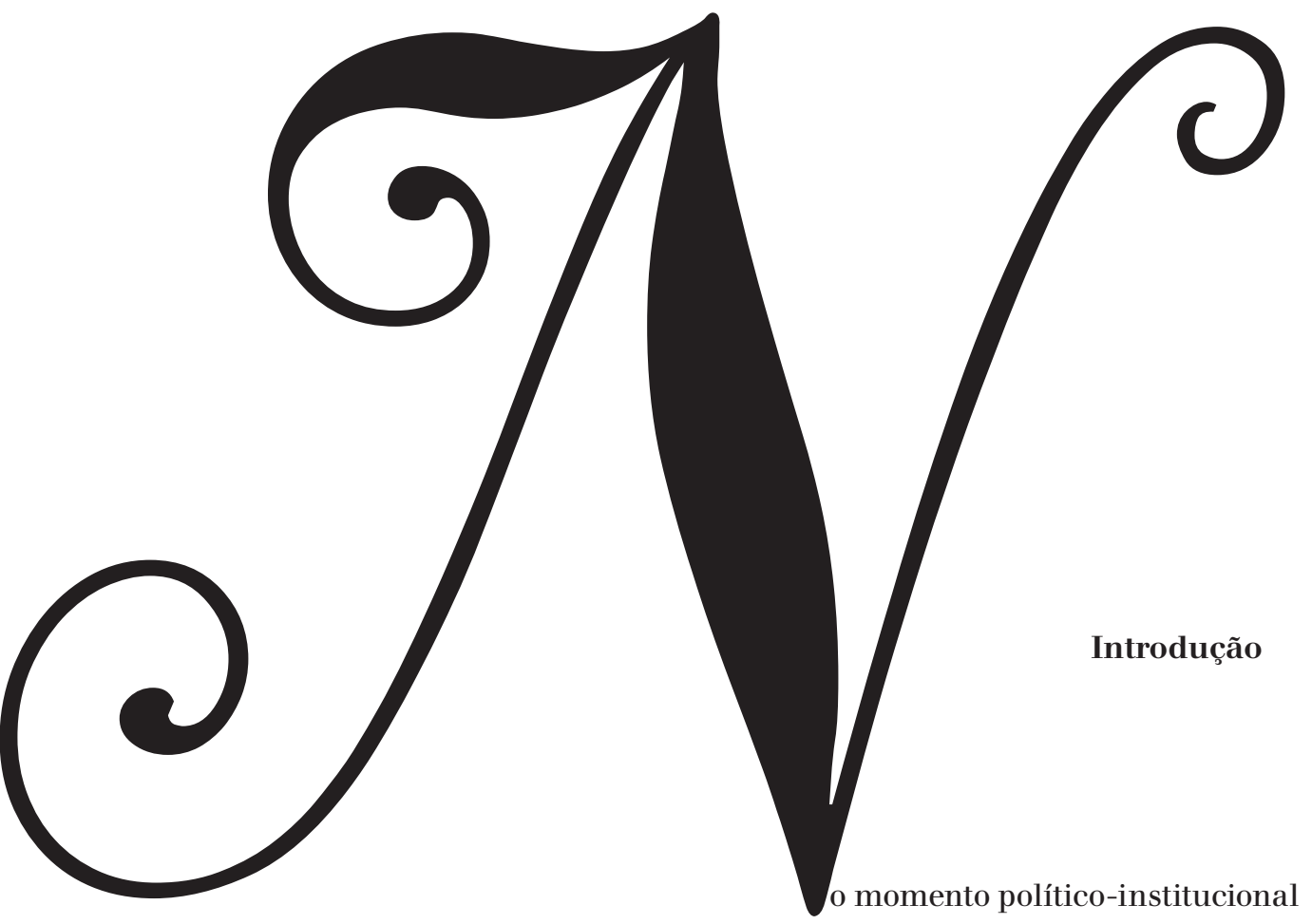
em que se considera a reabertura da Superintendência para o Desenvolvimento do Nordeste - Sudene ${ }^{3}$, o objetivo deste trabalho será localizar, na trilha do pensamento social brasileiro-nordestino (aqui representado por Gilberto Freyre, Josué de Castro e Celso Furtado) as concepções da região Nordeste como pobre, "região-problema", "região explosiva".

Sabe-se da importância decisiva que tais concepções tiveram para a intervenção estatal indutora do crescimento econômico, vigente na região entre 1960 e 2000, da qual a Sudene é a epítome. O que não parece claro é se a retomada da Sudene - cujas implicações normativas têm sido enfaticamente desautorizadas pelo atual ímpeto globalizante - significa a retomada de práticas inspiradas naquelas concepções. Seria possível, pois, falar da permanência de um discurso "pró-Nordeste" (e, eventualmente, mais favorável a um padrão diferenciado de intervenção estatal no Nordeste) inspirado em uma concepção de região carente, "insuficiente", formulada no âmbito do pensamento social brasileiro?

As concepções daqueles pensadores que nos interessam aqui, expressas em obras selecionadas de sua autoria e de comentadores ${ }^{4}$, serão

3 Quando de nossa revisão final deste artigo, surpreendeu-nos a notícia, de fevereiro de 2008 , dando conta da reabertura da Sudene, passados quase sete anos de seu fechamento.

4. Além dessas fontes, também se coligiu alguma bibliografia sobre o federalismo brasileiro, subjacente à nossa discussão. Como se pode constatar, a pesquisa que facultou a escritura deste artigo foi essencialmente bibliográfica. 
apresentadas na ordem de sua menção, feita acima, cada uma delas correspondendo a uma seção específica. Sobre a ordem dessa apresentação, cabe dizer que é reveladora a forma como germinou, na intelectualidade nordestina brasileira, a ideia segundo a qual a pobreza, tão caracteristicamente nordestina, só seria combatida se tal empreitada fosse levada adiante sob a forma de intervenção estatal corretiva.

Ademais, a cronologia é indicativa da transição que se processa, no "pensamento social nordestino", de uma intelectualidade tradicional para uma intelectualidade engajada, esta última defensora da intervenção. Transição essa que se deu, também, por força da dinâmica federativa brasileira: ante a regionalização do Estado Federal Brasileiro, fomentando padrões de maior ou menor cooperação entre os estados federados e a União para a satisfação de interesses econômicos e políticos.

Acontecimento-chave, aqui, seria a revolução de 1930, cujos impactos estendem-se até 1945. Neste interregno, o primeiro ciclo do federalismo brasileiro ${ }^{5}$ sofre uma espécie de interrupção, sem que, contudo, cessasse o recurso à União para o atendimento de demandas de natureza econômica. Ao contrário, este passou a ser, no caso nordestino, um expediente levado adiante sob a égide de uma "região", delimitada, aliás, às vésperas da década de 1920, e como área de uma intervenção específica do Governo Federal, quando da criação da Inspetoria Federal de Obras Contra as Secas (Ifocs), embrião do mais conhecido Departamento Nacional de

5 Correspondente à implantação do sistema, feita quando da proclamação da República e nas circunstâncias históricas em que esta se deu no Brasil-manu militari, de "cima para baixo" -, que determinou o "pontapé inicial" da hegemonia das províncias sulistas com São Paulo à frente, numa federação crescentemente assimétrica ao longo do século XX. Sobre o assunto ver CARVALHO, José Murilo de. Federalismo y centralización en el império brasileño: historia y argumento. In: CARMAGNANI, Marcello (Coord.). Federalismos latinoamericanos: México/ Brasil/ Argentina. México, D.F.: Fondo de Cultura Económica, 1993 e CARVALHO, Ricardo Ismael de. Nordeste: a força da diferença - os impasses e desafios da cooperação regional. Recife: Massangana, 2005 .

6 Dulce Pandolfi nota que para os estados do Norte (que então englobava as regiões Norte e Nordeste do Brasil) "a redefinição do jogo político provocada pelo movimento revolucionário de zo, atingindo as bases de sustentação e de domínio político dos estados do Sul [hoje Sul e Sudeste e, em certa medida, Centro-Oeste], poderia possibilitar a retomada de uma participação mais expressiva a nível nacional [...]. A concretização de tal objetivo exigia um instrumental forte que, na época, era visualizado na unidade política da região. Coeso, o Norte teria melhores condições para posicionarse e reconquistar o lugar que legitimamente sempre fora seu [sic] na esfera federal. Neste sentido é que a busca de uma atuação conjunta marcaria, no pós-193o, toda a história política da região [...] no pós-19zo a unificação política agiria como novo recurso de poder para a afirmação regional e o enfrentamento político do Centro-Sul”. PANDOLFI, Dulce Chaves. A trajetória do Norte: uma tentativa de ascenso político. In: GOMES, Ângela Maria de Castro (Coord.). Regionalismo e centralização política. Rio de Janeiro: Nova Fronteira, 1980. p. 343. 
Obras Contra as Secas (Dnocs). Desta delimitação, pinçaram-se características "regionais" que reforçariam a ação político-parlamentar em bloco para angariar, junto à União, as providenciais "verbas"7. Características entre as quais sobressairia e ocuparia cadeira cativa no imaginário brasileiro a notável desigualdade socioeconômica.

Na economia política do federalismo e na história regional brasileiras, parte da federação, um ajuntamento de Estados adquiriu unidade regional por suas debilidades, suas insuficiências demandantes de constante tutela estatal. E as sístoles e diástoles que acometeram o sistema federativo ao longo do século XX pairam sobre as concepções de Nordeste dos "pensadores nordestinos" selecionados (mas é em Celso Furtado que a associação entre federalismo e desenvolvimento regional é mais enfatizada ${ }^{8}$ ). Por sua vez, tanto a identificação da região Nordeste por suas debilidades, quanto os argumentos favoráveis à intervenção corretiva do Estado está explícita em dois deles: Celso Furtado e Josué de Castro. Caberiam, no entanto, a Gilberto Freyre, os primeiros movimentos no sentido de uma definição de "Nordeste".

\section{Gilberto Freyre: o Nordeste adocicado pela tradição e salgado pela modernidade}

O Nordeste, livro de Gilberto Freyre, de 1937, e o território surgem de duas fontes. A primeira seria o I Congresso Brasileiro de Regionalismo, realizado no Recife, em fevereiro de 1926. Vivia-se no Brasil, à época, sob a égide da política dos governadores em seus estertores. Nosso autor, como que se antecipando à destituição formal dos estados da Federação pela Revolução de 1930, propunha, com seu movimento regionalista, tradicionalista e, a seu modo, modernista do Recife deslocar o eixo do debate: das querelas políticas estaduais, cada vez mais assemelhadas às disputas internas vividas nos Bálcãs, para o conceito de regiões, a serem doravante pensadas como matrizes culturais, inibindo-se, assim, separatismos ${ }^{9}$.

7 Sobre este tema ver CASTRO, Iná Elias. O mito da necessidade: discurso e prática do regionalismo nordestino. São Paulo: Bertrand Brasil, 1992.

8 Por conseguinte, daremos mais ênfase, no desenvolvimento deste artigo, às idéias de Furtado.

9 Nos anos 1950, no Manifesto regionalista, Freyre registraria que uma das maiores injustiças “que se pode fazer a um regionalismo como o nosso seria confundi-lo com separatismo ou bairrismo... Ele é tão contrário a qualquer espécie de separatismo que, mais unionista que o atual e precário unionismo brasileiro, visa a superação do estadualismo, lamentavelmente desenvolvido aqui pela República - este sim, separatista - para substituí-lo por novo e flexível sistema em que as regiões, mais importantes que os estados, se completem e se integrem ativa e criadoramente em uma verdadeira organização nacional. [...] O conjunto de regiões é que forma verdadeiramente o Brasil. Somos um conjunto de regiões antes de sermos uma coleção arbitrária de estados, uns grandes, ou- 
O propósito do movimento seria o de zelar pelas expressões da cultura nordestina, suas tradições, defendendo-as do perigo de serem abandonadas pela voracidade de dirigentes que "passam por adiantados e progressistas pelo fato de imitarem cega e desbragadamente a novidade estrangeira. [...] Talvez não haja região no Brasil que exceda o Nordeste em riqueza de tradições ilustres e em nitidez de caráter"10. Está, assim, colocada a proposta de adotar a região como ferramenta metodológica.

A segunda fonte de (e do) Nordeste freyreano seria sua obra seminal, Casa-grande \& senzala, de 1933. Ali, como se sabe, ocupou-se de investigar a formação da sociedade brasileira sob um regime de "economia patriarcal" (nos termos de Freyre) e em uma "colônia de produção" (nos termos de Leroy-Bealieu) de açúcar, instalada, inicialmente, na faixa úmida do nordeste brasileiro.

Para além da importante e pioneira discussão ecológica, ou de "ecologia social ou humana", há em Nordeste aquela "microssociologia" tão freyreana, e há, ainda, um parti pris regionalista fundamental. Pois desagradava, então, ao mestre de Apipucos a circunscrição, algo desfiguradora, do Nordeste às áreas atingidas pelas secas: ao Nordeste das "obras contra as secas", que sugeriria quase nada, senão as secas. "Os sertões de areia seca rangendo debaixo dos pés", nesse Nordeste "de figuras de homens e bichos se alongando quase em figuras de El Greco [...] Apenas um lado do Nordeste"11. A sua região é outra, ou são outras:

Nordeste que vai do Recôncavo ao Maranhão, tendo o seu centro em Pernambuco. Aliás, há mais de dois Nordestes e não um, muito menos o Norte maciço e único de que se fala no Sul como exagero de simplificação. [...] O Nordeste do massapé, da argila, do húmus gorduroso é o que pode haver de mais diferente do outro, de terra dura, de areia seca. A terra aqui é pegajenta e melada. Agarra-se aos homens com modos de garanhona. [...] Há quatro séculos que o massapê do Nordeste puxa para dentro de si as pontas de cana, os pés dos homens, as patas dos bois, as rodas vagarosas dos carros, as raízes das mangueiras e das jaqueiras, os alicerces das casas e das igrejas, deixando-se penetrar como nenhuma outra terra dos trópicos pela civilização agrária dos portugueses. ${ }^{12}$

tros pequenos, a se guerrearem economicamente [...] em um jogo perigosíssimo para a unidade nacional. FREYRE, Gilberto. Manifesto regionalista. In: QUINTAS, Fátima (Org.). Manifesto regionalista. 7. ed. Recife: Massangana, 1996. p. 47-75.

10 Idem, ibidem, p. $5^{1 .}$.

11 FREYRE, Gilberto. Nordeste: aspectos da influência da cana sobre a vida e a paisagem do Nordeste do Brasil. 5. ed. Rio de Janeiro: José Olympio; Recife: Fundarpe, 1985 · p. 5. Idem, ibidem, p. 6. Note-se que Freyre usa ambas as formas, "massapé" e "massapê". 
Ressalta, contudo, que "não nos interessa aqui, senão indiretamente, a análise do massapê e das terras argilosas e gordas de húmus do Nordeste do Brasil. Nos interessa [sic] só o que essa terra excepcional representou para a civilização do Brasil"'13. Daí que seu Nordeste seja Nordeste: aspectos da influência da cana sobre a vida e a paisagem do Nordeste do Brasil. Terras desse solo massapé que Gilberto Freyre puxou para dentro de si, e que via agonizar, em plena crise da economia açucareira pernambucana, já suplantada pela pujança industrial de São Paulo. O que mais morreria com ele?

Desde logo, os tipos aristocrata e popular, arredondados por sedentários, produtos daquele barro avermelhado, que degeneraram em usineiros e em trabalhadores pobres adoentados. E que fizeram, junto com o a empresa latifundiária e o industrialismo, terra, água e matas adoecerem, porquanto a natureza regional "tende, não há dúvida, a fazer o homem, o grupo, a cultura humana à sua imagem; mas, por sua vez, o homem, o grupo, a cultura humana agem sobre a natureza regional, alterando-a de modo às vezes profundo"14. Equilíbrio que Freyre percebia ameaçado, pois o monocultor rico do Nordeste havia feito das águas dos rios nordestinos

um mictório [...] de caldas fedorentas de suas usinas. E as caldas fedorentas matam os peixes [...] Os peixes mais finos fedendo de podres, ao lado dos mais plebeus. O cheiro de peixe podre misturando-se ao de fruta podre, das margens sujas dos rios.

Quase não há um rio do Nordeste do canavial que alguma usina de ricaço não tenha degradado em mictório. As casas já não dão a frente para a água dos rios: dão-lhe as costas com nojo. ${ }^{15}$

Esse dar as costas à natureza, voltando-se os novos senhores da terra para o artificialismo das prioridades econômicas, era também um dar as costas à Tradição - esse, o maior receio de Freyre. Receio de que a usina moesse a sociedade tradicional que brotara da terra "garanhona". Que se destruísse, por força do projeto da modernidade, a "antiga civilização do Nordeste", que mesmo portadora de suas patologias sociais, quando comparada com outras civilizações brasileiras (tais como a do couro ${ }^{16}$, a das minas e a do café), delas se distancia por ser a mais fértil em "valores políticos, estéticos culturais"17. Ostra que dá pérola, que a empresa modernizadora e capitalista ameaçava

13 Idem, ibidem, p. 9 .

14 Idem, ibidem, p. xxii.

15 Idem, ibidem, p. 35 .

16 A do Outro Nordeste, de Djacir Menezes (publicado em 1937 pela mesma coleção da José Olympio).

17 FREYRE, Gilberto. Nordeste: aspectos da influência da cana sobre a vida e a paisagem do Nordeste do Brasil. op.cit., p. 177. 
extinguir. Pioneiro, Freyre "inventa" um Nordeste puxado do passado e daquele massapé "acomodatício” das relações sociais. E aqui se afirma, em mais uma de suas tantas obras, o seu projeto conservador.

Freyre tece uma unidade imagético-discursiva que toma como base o Nordeste açucareiro, já que a região de terras duras e secas seria mais propícia para servir de base a um discurso cuja estratégia fosse a denúncia das condições sociais da região. O Nordeste do açúcar serve mais prontamente para seu projeto de resgate de um passado de poder e riqueza que viesse a compensar exatamente os problemas sociais e a decadência crescente dessa área do país. ${ }^{18}$

Contudo, sua interpretação não se dá conta de que não somente aquele seu Nordeste, mas todo o Nordeste, úmido ou seco, do açúcar ou do couro, para além de uma entidade regional diferenciada, era também, como observa Mendes Júnior, "um signo de deterioração, de calamidade ininterrupta, de homogeneização de miséria"19. É, nessa forma, mais Nordeste, a construção de Josué de Castro.

\section{Josué de Castro e o Nordeste como "barril de pólvora"}

Sobrevindo o golpe militar de 1964, que depôs João Goulart, imediatamente após a entrega dos originais de Sete palmos de terra e um caixão, à edição inglesa, ocorreu a Josué de Castro, seu autor, o que registra na Introdução à terceira edição, solicitá-los de volta, imbuído que estava de incluir no trabalho original um capítulo que tratasse desse episódio, "tão ligado em suas origens e em sua expressão política à luta que se [vinha] travando com intensidade crescente no Brasil, entre as fôrças de emancipação nacional e as fôrças [sic] de contenção do desenvolvimento econômico-social do país"20.

Suspeitava o autor que o acirramento dos conflitos sociais, culminando no Golpe, era também tributário de acontecimentos que, havia pelo menos uma década, tinham como palco o Nordeste rural. Lúcida suspeição. Assim, logo adiante, no primeiro capítulo, Castro registra, não sem

18 ALBUQUERQUE JR., Durval Muniz de. A invenção do Nordeste e outras artes. Recife: FJN, Massangana; São Paulo: Cortez, 1999. p. 100.

19 MENDES JÚNIOR, Alcides. Pa(lavras) em terra: forja e coifa de uma região: espaço e discurso na literatura regionalista nordestina. Recife: Editora Universitária da UFPE, 2006. p. 67 .

20 CASTRO, Josué de. Sete palmos de terra e um caixão: ensaio sobre o Nordeste, uma área explosiva. 3. ed. São Paulo: Brasiliense, 1969. p. 11. 
estranheza, que, em meados da década de 1950, a fundação da primeira das Ligas Camponesas ocorrera com o objetivo inicial de assegurar aos camponeses da região açucareira, "mortos na extrema miséria da bagaceira" 21 , 0 direito a uma morte "digna" - isto é, "o direito de dispor de sete palmos de terra onde descansar os seus ossos e o de fazer descer o seu corpo à sepultura dentro de um caixão de madeira de propriedade do morto, para com êle [sic] apodrecer lentamente pela eternidade afora" ${ }^{22}$. Que, para o campesinato nordestino a morte - esta, sim, certa, garantida - contasse mais do que a vida, só faz sentido ante o registro de que

[a] larga experiência de mais de quatro séculos de um regime agrário de tipo feudal - ali implantado pelos colonos portuguêses [sic] sob a forma do latifúndio escravocrata, produtor de açúcar [...] - e a resistência invencível dêste [sic] regime em ceder a qualquer exigência ou reivindicação dos camponeses para melhorar um pouco suas trágicas condições de vida acabaram por dar a esta gente o sentimento da inutilidade de qualquer esfôrço [sic] para sair do atoleiro de sua miséria. ${ }^{23}$

Está-se aqui a léguas de distância - sem que se saia do lugar... do Nordeste açucareiro de Freyre, aquela "terra garanhona" de homens açucarados, ou, antes, intoxicados pelo açúcar e por seu fabrico, que anestesiava os seus sentidos para a doce exploração a que eram submetidos. O homem nordestino de Josué de Castro - ali na mesma zona da mata de Gilberto Freyre - desperta para revoltar-se contra a sua condição de espoliado, de miserável em meio à doce riqueza que produzia. A criação das Ligas Camponesas, pelas reações que produziu nos senhores de engenho, conta a história desse despertar.

Concebidas inicialmente como sociedades de auxílio mútuo para o financiamento de serviços funerários, enquanto foram assim vistas puderam granjear a simpatia do patronato. Contudo, não tardaria para que fossem identificadas como "células" da agitação social e do comunismo, que rondava a região desde os anos de 1930. Iniciam-se, assim, as exigências de fechamento imediato das Ligas, pelo que começa a resistência. Os "camponeses" nordestinos, resignados ao direito garantido da morte, despertam para a vida. Teria de ser assim.

Criada para defender os direitos dos mortos, ela [a Liga] iria agora se constituir como instrumento de reivindicação dos direitos dos vivos.

21 Idem, ibidem, p. 25 .

22 Idem, ibidem.

23 Idem, ibidem, p.26. 
Mas, não é mesmo morrendo que melhor se aprende a viver? Pelo menos no Nordeste brasileiro. Foi tratando dos problemas da morte que os camponeses do Engenho Galiléia [local de fundação da primeira Liga] abriram os olhos para a vida. E viram melhor, e melhor compreenderam as injustiças da vida e quais eram os autores dessas injustiças. ${ }^{24}$

O Nordeste de Josué de Castro é fundamentalmente um rincão cujo “traço mais marcante... é o sofrimento. E não apenas o sofrimento do homem, mas também o sofrimento da terra" ${ }^{25}$. Sofrimentos a que subjazem duas descobertas, historicamente delimitadas. A primeira ocorrera no século XVII: a descoberta, pela empresa colonial portuguesa, do massapé nordestino, permitindo a implantação da monocultura açucareira, que progressivamente degradou a riqueza daquele solo, deixando-o faminto de elementos minerais e húmus (não esqueçamos: a verve ensaística de Castro é a de um homem das ciências naturais, comprometido com as questões sociais nordestinas). Terra faminta, homem faminto. "A fome aparecendo como uma espécie de subproduto da economia da cana, e os famintos como uma forma de bagaço de sua estrutura social: o bagaço humano do latifúndio açucareiro" ${ }^{26}$, que, privado de uma dieta equilibrada em calorias, cansa-se ao menor esforço, mostra-se indolente. Seria este o homem "açucarado" de Gilberto Freyre ${ }^{27}$ ?

Contraposta à fome do homem da zona-da-mata, a fome do sertanejo, habitante do semi-árido nordestino - onde foi possível a introdução do gado vacum, de caprinos e suínos e de alguma policultura, mesmo que em regime de roçado, tudo isto possibilitando uma dieta mais equilibrada, ainda que eventualmente "espartana" - varia conforme o regime de chuvas. Quando estas escasseiam, e por muito tempo, levando às estiagens e às secas prolongadas, em pequenas e delimitadas áreas ou mais extensamente em grande parte do território semi-árido, desorganizam-se as soluções econômicas garantidoras da vida naquela terra inclemente ${ }^{28}$.

24. Idem, ibidem, p. 33 .

25 Idem, ibidem, p. 4,o.

26 Idem, ibidem, p. 59 .

27 O mestre de Apipucos estava ciente dos processos destrutivos da ecologia humana no Nordeste, impostos, desde a colônia, pelos interesses econômicos portugueses. Ver, por exemplo, sua discussão sobre a pobreza da dieta de senhores de engenho, agregados e escravos, no capítulo I de Casa-grande \& senzala. Pretendeu-se afirmar a "doçura" da região, mas seus motes foram outros, como discutido acima.

28 Ante as estiagens, todos os envolvidos na produção no semi-árido perdem; mas é fato que uns perdem mais que outros. A perversa lógica econômica da seca, num quadro de concentração de propriedade fundiária notável e crescente ao longo do século XX - perpetuando até hoje relações de renda e de classe arcaicas - converte um fenômeno climático desastroso numa calamidade pública, que segue atingindo dezenas de milhões de pessoas ("grandes secas", estiagens prolongadas como as de 1979-83 e de 1987, atingiram 
Reaparece assim o traço mais distintivo do Nordeste: a seca, e com ela o homem flagelado pela "penúria orgânica" que este fenômeno impõe: “o esquizotímico, com sua curva de temperamento instável” ${ }^{29}$, eis o diagnóstico do Dr. Castro. Mas, seria o caso de ater-se a estas considerações médicas, ao determinismo dos "males de raça” e dos "males de clima"? À base deles o homem nordestino,

o cabeça-chata [...] passou a ser retratado como um judeu-errante brasileiro, o eterno emigrante, que estão sempre estendendo a mão no ar para ver se está chovendo, e sempre que a chuva não está caindo, dispara êle [sic] aterrorizado pelo campo afora, fugindo da terra amaldiçoada e virando a mão estendida, com sua palma para cima, no gesto tradicional de quem pede esmola, de quem implora a caridade pública. ${ }^{30}$

O que nos leva à segunda descoberta narrada pelo autor: a do Nordeste pelos norte-americanos que, na década de 1960, constatam um suposto potencial revolucionário regional canalizado pela atuação das Ligas. O registro histórico dessa "segunda descoberta", a conhecida reportagem de Tad Szulc sobre o Nordeste, publicada no The New York Times, em 31 de outubro e 1 de novembro de 1960, que causou grande polêmica na opinião pública estadunidense. Tudo indicava, segundo Szulc, que a partir da capital de Pernambuco, então "o mais forte centro comunista do Brasil”, encontrava-se germinando um movimento revolucionário à chinesa ou à cubana, que não tardaria em explodir o barril de pólvora da pobreza nordestina.

cerca de 25 milhões de pessoas). As famílias sertanejas de baixa renda em sua maioria se dedicam à agricultura de subsistência, por vezes complementada pela pequena criação de gado e pelo algodão, cultivado em pequenas unidades. Nesse esquema produtivo, uma quebra de safra é fatal, como destaca o pesquisador Renato Duarte: "devido ao baixo rendimento médio da agricultura, os pequenos proprietários e os trabalhadores que cultivam terras alheias não conseguem formar excedentes de que possam fazer uso em períodos de seca. Desse modo, ao se defrontarem com a falta de alimentos e de água para consumo familiar e dos rebanhos, eles tampouco dispõem de renda monetária para a aquisição de víveres no mercado. Assim, a seca provoca, simultaneamente, a desarticulação da oferta de alimentos (e de matérias-primas vegetais) e a redução da renda agregada. A queda simultânea da oferta e da demanda agregadas provoca, naturalmente, aumento dos preços dos gêneros de primeira necessidade, inclusive de água em muitas localidades. (O preço da carne pode cair em decorrência tanto da diminuição do poder aquisitivo da população quanto da necessidade que tenham os donos dos rebanhos de vendê-los)". DUARTE, Renato. A seca no Nordeste: de desastre natural a calamidade pública. In: LIMA, João Policarpo (Org.). Economia e região, Nordeste e economia regional: ensaios. Recife: Editora Universitária da UFPE, 1999. p. 203 [grifo nosso].

29 CASTRO, Josué de. op.cit., p. 89.

zo Idem, ibidem, p. 170 . 
Para o nosso ilustre médico e nutricionista pernambucano o ledo engano de Szulc residia em sua incapacidade de "decifrar o enigma do Nordeste". Faltavam-lhe conhecimentos específicos da história regional nordestina, “dos seus antecedentes remotos e da transformação mais recente processada na consciência do povo brasileiro a partir do comêco dêste [sic] século" ${ }^{31}$. A segunda descoberta só serviria de critério de entendimento, de decifração, à base da primeira descoberta, e, na verdade,

a tensa explosividade do Nordeste [era] um produto da evolução natural de sua estrutura sócio-econômica superada e inadequada para dar atendimento aos desejos e aspirações de um povo que, tendo finalmente, tomado consciência de sua existência como entidade política, procura dar expressão a seus anseios de reforma e de melhoria de suas desumanas condições de vida. ${ }^{32}$

Aqui Josué de Castro afirma a sua filiação àquela corrente de pensadores que Albuquerque Jr. enquadra como comprometidos em promover certa "inversão do Nordeste". Uma inversão da concepção de Nordeste, que até a década de 1950 teve em Gilberto Freyre seu autor de referência. Tratou-se de inverter, à base da crescente influência do marxismo - uma das fontes em que beberia a intelectualidade de esquerda brasileira -, substituir o impressionismo do "homem sob o Nordeste" pela denúncia social do "povo do Nordeste": da "terra garanhona" à terra seca; da estética tradicionalista à estética pré-revolucionária; do Nordeste que se tinha (ou que se teve, evocando Freyre) ao Nordeste que se queria.

Se a sociologia freyreana havia sido responsável, em grande parte, pela visibilidade e dizibilidade [sic] tradicionalista do Nordeste, a influência do pensamento marxista vai ser decisiva para emergência desta nova forma de ver e dizer o Nordeste [...]. Assim como a negação do presente pode ser feita por uma volta ao passado, como ocorreu com os tradicionalistas, ela pode se dar também por uma busca de antecipar o futuro, de construí-lo, a partir do presente, de fazê-lo viver no presente. A reterritorialização revolucionária é uma forma de reconstruir um novo território no futuro, que viesse a substituir o desconforto com a sociedade do presente. ${ }^{33}$

31 Idem, ibidem, p. 154-155.

$3^{2}$ Idem, ibidem, p. 155 .

33 ALBUQUERQUE JR., Durval Muniz de. op. cit., p. 184. 
Este esforço de dotar o Nordeste de nova "dizibilidade", nos termos do autor citado, já estava em construção, vale dizer, desde meados dos anos de 1930. Confirma-o O outro Nordeste, de Djacir de Menezes e a Geografia da fome, o grande clássico do Dr. Castro, publicado nos anos de 1940. Permaneceriam obras em certa medida isoladas, contudo, pela ausência de terreno fértil - mais metáfora do que trocadilho! - onde se afirmassem. Será somente a partir de 1945, momento em que se afiança um novo pacto federativo $^{54}$, e sob a égide do discurso nacional-desenvolvimentista/cepalino, que a região nordestina emerge como "problema nacional". E as décadas de 1950 e 1960 viverão o seu o momento furtadiano por excelência.

\section{Celso Furtado e o Nordeste como periferia e "problema"}

O que nos leva a uma breve apreciação da estrutura econômica do Nordeste prévia à industrialização incentivada, iniciada nos anos de $1960^{35}$. A transferência do eixo de acumulação de capital do setor primário-exportador para o industrial, pela via da substituição de importações - fartamente documentada na literatura sobre economia brasileira -, veio bater às portas do Nordeste um quarto de século depois de iniciada no Sudeste, propondo novos arranjos na divisão inter-regional do trabalho brasileira. O verdadeiro surto que caracterizaria a industrialização pesada, sob a égide do Plano de Metas, reacenderia a chama dos debates sobre a desigualdade mais ao Norte. Tais debates integravam outros tantos a nível nacional, suscitados pelo impasse a que havia chegado o processo de acumulação de capital industrial naquela região.

A esses debates calorosos somar-se-ia, em 1958, a fagulha de uma grande seca. Ante a dimensão dos impactos sociais de mais uma estiagem

34. "A segunda experiência federalista [brasileira] começou em 1945 e terminou com o golpe militar de 1964. Neste intervalo, vai prevalecer no Brasil, sob a influência dos ambientes europeu e norte-americano, o chamado federalismo cooperativo, no qual o governo federal amplia a sua participação no planejamento e na execução de políticas públicas voltadas para o desenvolvimento das unidades da federação [...]. A Constituição de 1946 deu início à prática de transferências constitucionais da União para a solução de problemas nordestinos, destinando um total de $3 \%$ dos impostos federais para o desenvolvimento das áreas atingidas pela seca no Nordeste. Além disso, foram criadas, no período, políticas federais dirigidas para a integração das regiões brasileiras e a redução das desigualdades regionais". CARVALHO, Ricardo Ismael de. Nordeste: a força da diferença - os impasses e desafios da cooperação regional. op. cit., 2005. p. 98.

35 Os seis parágrafos seguintes reproduzem, em parte, argumentos originalmente apresentados em MARTINS, André Luiz de Miranda. Estado e força de trabalho no Nordeste: ocupação no setor público e aposentadorias rurais na década de 1990 . Tese de doutorado. Campinas, SP: IE/ Unicamp, 2004. 
- notoriamente a ampliação considerável do contingente de migrantes forçados, observada já a partir da seca de 1951-53 - que demonstrou a clara insuficiência das "soluções hidráulicas", isto é, a açudagem paliativa, os debates sobre a questão regional nordestina evidenciavam o grau de conscientização política a que havia chegado uma parte das elites, dentro e fora da região.

Esse inteirar-se do fenômeno das secas como um condicionamento "geográfico" que evidenciava as carências econômicas regionais, claramente expressas que estavam em desníveis consideráveis de renda, tornava, pois, premente a adoção de solução alternativa àquela hidráulica, correntemente adotada. Além da estiagem e dos movimentos migratórios (novamente) deflagrados, um fator mais, digamos, técnico aumentaria a pressão social por novas "soluções" para o Nordeste: em 1951 e em 1952, com a divulgação das contas nacionais e regionais do Brasil, as desigualdades de renda interregionais teriam sua magnitude precisamente mensurada ${ }^{36}$.

Muito embora fossem esses três fatores os que verdadeiramente incendiariam os debates sobre a "região-problema", em meados dos anos 1950, é fato que já havia mais de um decênio que a percepção institucional dos problemas estruturais do Nordeste não se mantinha petrificada como as relações de renda que ali, em boa parte de seu território, grassavam. Prova disso seria o estabelecimento da Companhia Hidrelétrica do Vale do São Francisco (Chesf), em 1945, e a criação da Comissão do Vale do São Francisco, em 1948. Ambas pareciam materializar a percepção de que a irrigação era uma necessidade premente.

Assim, passava-se da ênfase na açudagem, que, de todo modo, havia deixado como "legado" de quase meio século algum capital físico disponível, para a ênfase nas potencialidades da irrigação, que possibilitaria o incremento da produtividade dos capitais porventura investidos na região. Subjazia a tais mudanças institucionais o reconhecimento de que pouco se havia logrado quanto ao fortalecimento da economia da região pelo recurso às obras "contra" as secas, empreendidas pelo governo federal ${ }^{37}$.

$3_{6}$ "Pelos censos industriais de 1919 e 1949, podia-se constatar que as taxas médias anuais de crescimento industrial foram de 7,9\% em São Paulo e de 5,4\% para o resto do país e que São Paulo concentrava entre 50\% e 70\% do valor adicionado pelas indústrias produtoras de bens de produção. Em suma, ficava cada vez mais claro que os desequilíbrios regionais tendiam a se acentuar e que poderiam aumentar, em face dos maciços investimentos de infra-estrutura e de indústria pesada decorrentes do programa de metas, que se concentravam principalmente em São Paulo, e isso desencadeava pressões políticas das demais regiões, reclamando tratamento prioritário de desenvolvimento" CANO, Wilson. Ensaios sobre a formação econômica regional do Brasil. Campinas: Editora da Unicamp, 2002. p. 127.

37 Ou seja: já havia intervenção governamental no Nordeste; contudo, esta não era corretiva - ou, como "transformacional". VELHO, Otávio Guilherme. Capitalismo autoritário 
A ênfase na irrigação, ao que tudo indicava, "impunha novas concepções, retirando o problema do âmbito da engenharia para situá-lo numa esfera de consideração socioeconômica e técnico-jurídica"38.

Outra via pela qual se materializariam essas novas concepções que se impunham seria a criação do Banco do Nordeste do Brasil (BNB). Criado por indicação do banqueiro paulista Horácio Lafer, à época Ministro da Fazenda, o BNB surgiria como banco de investimento e desenvolvimento, instrumento financeiro voltado especialmente para a expansão do cultivo do algodão arbóreo, "mocó", esse velho conhecido de oligarcas e sertanejos. Assim, a partir da segunda metade dos anos 1950, com o apoio financeiro do BNB, bem como com a Petrobrás e a Chesf em operação promovendo, entre 1955 e 1959, um aumento da oferta de energia elétrica de 145\% nos mercados por ela servidos - algo novo, pelo menos em termos da infra-estrutura disponível, parecia estar em curso no Nordeste.

Também a produção técnica e científica sobre o Nordeste e seus problemas havia avançado substancialmente. Já se sabia que tais problemas não eram tão-somente devidos a um fenômeno natural, pelo que também a sua resolução exigia medidas para além das "hídricas", (ainda que políticas de proteção hídrica continuassem sendo necessárias, conquanto não se esgotassem no atendimento emergencial e dessem azo ao assistencialismo de sempre). Na década de 1950, essa produção técnico-científica avançaria consideravelmente com a criação, pelo BNB de um escritório de estudos técnicos sobre a economia nordestina, o Etene. Aprofundar-se-ia, assim, a compreensão sistêmica dessa economia regional, bem como se formaria toda uma geração de economistas dotados de conhecimento mais específico sobre a região.

Entra em cena Celso Furtado, que à época já portava vasto currículo de serviços prestados à Comissão Econômica para a América Latina e o Caribe (Cepal). Sob sua batuta aprofunda-se ainda mais o conhecimento técnico do sistema nordestino. Instituem-se a "Operação Nordeste", o Conselho de Desenvolvimento do Nordeste (Codeno) e o Grupo de Trabalho para o Desenvolvimento do Nordeste (GTDN). Do trabalho deste Grupo surgiria o famoso relatório do GTDN, intitulado Uma políticadedesenvolvimento para o Nordeste. A ação governamental na região adquiria "uma profundidade e extensão que a levou a perder consideravelmente o seu tradicional 'caráter espasmódico'

e campesinato. São Paulo: Difel, 1976. Numa crítica ao gasto público feito na agropecuária nordestina, Furtado dispara: "[a] política do governo de subsidiar o açúcar e de financiar a fundo perdido a construção de açudes em benefício da pecuária extensiva bloqueia o setor agrícola produtor de alimentos, agravando o quadro de pobreza". FURTADO, Celso. A fantasia desfeita. 3. ed. Rio de Janeiro: Paz e Terra, 1989. p. 44.

38 ALBUQUERQUE, Roberto Cavalcanti de e CAVALCANTI, Clóvis de Vasconcelos. Desenvolvimento regional no Brasil. Brasília: IPEA, 1978. p. 61. 
e o seu papel de reforço não-transformacional da classe dominante. Levou à

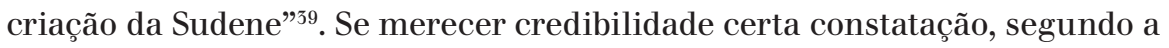
qual até meados do século XX o Estado era tudo - ou quase tudo - para um nordestino, fosse ele coronel, usineiro ou "povo", é de se crer que o Estado, assim, como a sua Paraíba do Norte de origem, não tenha saído da cabeça de Celso Furtado. E que a inteligibilidade daquela necessidade esteja presente - recolocando-se para a segunda metade do século, ainda que sob formas outras - no conjunto de sua produção sobre o Nordeste, da qual destacamos Formação econômica do Brasil, de 1956, e A operação Nordeste, de $1959^{40}$. O primeiro é certamente o mais importante estudo sobre a história econômica brasileira, em que Furtado dá o pedigree teórico-econômico de suas concepções "estadocêntricas" ${ }^{41}$; no segundo, o Nordeste é localizado como problema técnico e político, cuja resolução requer a intervenção estatal. No que procede nos concentraremos nesta concepção e em suas implicações para os destinos da "região-problema".

No diagnóstico furtadiano o atraso nordestino ante a economia sudestina, sua "fratura estrutural" ", constatava-se na esterilização dos ganhos com a exportação de bens primários e pelas compras de bens industrializados no "Centro-Sul", nos marcos de uma política cambial desfavorável aos estados do Nordeste. Atraso reforçado a) pela concentração da propriedade fundiária, fiel da monocultura açucareira nas zonas úmidas e do complexo algodão-pecuária nas sub-regiões secas; e b) pela industrialização ausente, ou pela ausência de "um centro autônomo de expansão manufatureira”.

A segunda causa advinha da primeira: a monocultura açucareira impedia a diversificação agrícola, encarecendo a reprodução da força de trabalho (pela dificuldade de incrementar a oferta de alimentos), ao passo que o complexo algodão-pecuária sobrevivia à base da manutenção de relações de renda e propriedade arcaicas e de seu forte traço

39 VELHO, Otávio Guilherme. op.cit., p. 181.

40 O relatório do GTDN, ainda que não assinado por Furtado (por ser um documento oficial), é clara expressão de suas ideias.

41 "A importância ideológica de Celso Furtado e do seu keynesianismo que explicava a transição [da economia cafeeira para a industrial, durante o I Vargas, através da política de queima dos excedentes de café para manter os níveis de renda interna], nos anos 1950, e, por que não o dizer, até hoje, o pano de fundo do 'amor ao Estado' da burocracia econômica nacional. Essa 'autonomia' do gasto estatal, capaz de construir pirâmides que mantém a renda interna, formou gerações de cientistas sociais e, principalmente, de economistas cuja participação foi relevante na gestão da economia pelo Estado durante todo o período populista" OLIVEIRA, Francisco de. A navegação venturosa: ensaios sobre Celso Furtado. São Paulo: Boitempo Editorial, 200z. p. 20.

FURTADO, Celso. Afantasia desfeita. op.cit., p.52. 
econômico autárquico ${ }^{43}$. Ali as "crises de produção", que as estiagens periódicas evidenciavam, e cujo peso era sentido em larga medida pelo sertanejo pobre e sem-terra - anteriormente à seca ou em consequência dela -, resolviam-se pela intervenção governamental (obras "contra" as secas, organização de frentes de "trabalho", estas talvez o "programa de emprego" mais abrangente até hoje implantado ${ }^{44}$ ) e/ou pela migração forçada, geralmente para fora da região.

Uma industrialização que se espera promotora do desenvolvimento, mas impedida de ser autônoma terá de ser, assim, uma industrialização planejada, incentivada.

Estamos em plena euforia da industrialização kubitschekiana: também o Nordeste somente conseguirá sair da situação de "periferia", vencer o subdesenvolvimento, se se industrializar. Os interesses das classes sociais nacionais são resolvidos em torno da industrialização: de fora, apenas os latifundiários do Nordeste, e não

43 Eis uma das grandes contribuições de Furtado ao entendimento da economia brasileira: a interpretação, a partir de um uso seletivo do instrumental teórico da economia neoclássica, do papel da estrutura agrária no subdesenvolvimento brasileiro. Aqui o dualismo encontra sua mais clara expressão: “A economia principalmente de subsistência, no Brasil, assume assim duas formas: o domínio pecuário que se vê privado de mercados e tende a fechar-se sobre si mesmo, e o pequeno produtor agrícola ou sitiante que ocupa terras que ainda não foram alcançadas pela empresa agro-mercantil. Essas atividades, se bem que secundárias do ponto de vista econômico, tiveram marcada significação na formação da sociedade brasileira. O grande domínio pecuário que reduz os seus contatos com o exterior, limitando-os muitas vezes à venda de couros e à compra de umas poucas coisas essenciais, tende a diversificar-se internamente, incorporando lavouras de subsistência e atividades artesanais. Esse tipo de formação social, em que as atividades comerciais se reduzem a um mínimo, contrasta com a empresa agrícola agro-mercantil de que se originou. Esse contraste, entretanto, é mais aparente que real, porquanto numa e noutra se manifesta o mesmo perfil de estratificação social e extrema concentração da riqueza, da renda e do poder. Assim, se nas zonas pecuárias o estilo de vida do trabalhador ou 'morador' se assemelha ao das economias de subsistência, não se pode dizer o mesmo da forma de viver do proprietário das terras, o qual se apropria da reduzida renda monetizada e mantémse em contato com o exterior. Do ponto de vista da classe dirigente, o grande domínio do hinterland pecuário continua a ser uma atividade mercantil, ainda que empobrecida pelo declínio dos mercados que absorviam sua produção comercial. Toda vez que se reavivem esses mercados, o coeficiente de comercialização e monetização das atividades do hinterland pecuário se elevará". FURTADO, Celso. Análise do "modelo" brasileiro. 2. ed. Rio de Janeiro: Civilização Brasileira, 1972. p. 96-97.

44. Dados que coligimos em Martins (op. cit.) contabilizam um contingente de 8,11 milhões de alistados nas frentes de trabalho organizadas pelo governo (Federal, geralmente) nas secas de 1958, 1970, 1976, 1979-83, 1987, 1990-93 e 1998-20oo - quando passaram a ser chamadas de "frente produtivas". Na grande seca de 1979-83 as razões alistados/população atingida e alistados/força de trabalho ocupada no setor primário chegaram a 12,5 e 13,3 (em 1980), respectivamente. 
precisamente os barões-ladrões [sic] do açúcar, mas os do complexo algodão-pecuária, os coronéis. ${ }^{45}$

E que terá de ser feita! Pois a manutenção das desigualdades regionais criará as condições "para a cristalização de um antagonismo, de um ressentimento que o tempo simplesmente não resolverá" ${ }^{46}$. Não cuidar do equacionamento da "questão regional" nordestina equivalia, assim, a descuidar da segurança nacional, a acenar para o esfacelamento da federação. Para além de um encaminhamento técnico da "questão" - neste caso, os meios já estavam dados, pois havia uma análise da realidade que convidava à sua transformação, bem ao estilo manheimiano que tanto agradava a Furtado -, há um encaminhamento político a ser providenciado. A insistência nessa providência revela a força do federalismo no pensamento de Furtado. As coisas na sua devida ordem: o planejamento econômico voltado ao desenvolvimento regional - que tinha na Sudene o seu operador - seria a diretriz técnica de uma cooperação política horizontal, com os governadores dos estados da região à frente das deliberações ${ }^{47}$.

\section{Conclusão: três autores sobre a mesa e um esboço de comentário geral}

É difícil exagerar com respeito ao Nordeste do Brasil.

Aí tudo escapa a constatações fáceis.

Celso Furtado

Nordestização é uma medida econômica, um "metro" para medir uma situação social.

Gilberto Freyre

45 OLIVEIRA, Francisco de. A navegação venturosa: ensaios sobre Celso Furtado. op.cit. p. 22.

46 Idem, ibidem, p. 23.

47 É patente, em Furtado, o seu entendimento da política como pairando acima das querelas partidárias. E dos técnicos como verdadeiras entidades delas apartadas. Donde o seu alerta, segundo o qual o desenvolvimento econômico "deve ser desenvolvimento político-econômico [...] Economistas e outros técnicos têm fracassado na política porque tentaram transformar-se em políticos de partido. Deve-se ser político, mas não de partido. A batalha política deve tomar impulsão em termos da fortaleza do técnico". Depoimento citado em: MALLORQUíN, Carlos. Convite a uma leitura de Celso Furtado. In: FORMIGA, Marcos e SACHS, Ignacy (Coords.). Celso Furtado, a Sudene e ofuturo do Nordeste. Recife: Sudene, 2ooo. p.88. 
O traço mais marcante da cara ou fisionomia do Nordeste é o sofrimento. Josué de Castro

Das concepções de Nordeste aqui apresentadas, a que efetivamente daria o tom da intervenção estatal corretiva de desigualdades regionais foi, claro, a de Celso Furtado. Mas a história econômica do Brasil posterior ao golpe militar de 1964 está aí para desautorizar tentativas de creditar ao mestre os desmandos ocorridos na Sudene ao longo de sua existência. Voluntarismos à parte, as aspirações subjetivas desse "demiurgo do Nordeste" (o termo é de Francisco de Oliveira), cerne mesmo de sua proposta desenvolvimentista regional - a revisão transformadora das relações de propriedade fundiária e a criação, flagrantemente contrária aos "mecanismos de mercado", de um empresariado nordestino genuíno - esbarrariam na marcha da acumulação de capital verificada nos anos de 1960.

Os destinos do Nordeste desde então foram bem documentados: a região industrializou-se complementarmente ao Centro-Sul, reforçando a integração econômica preexistente; demandaram-se mais tratores e máquinas do que empregos industriais; o setor terciário inchou com o inchaço das metrópoles regionais, cujas classes médias e altas se equipararam às do Centro-Sul; o semi-árido nordestino tornou-se cada vez mais populoso e mais urbano: mais sede para as mesmas estiagens recorrentes.

Pelo lado da política e do Estado, esvaziou-se o quanto antes o princípio federativo subjacente à proposta furtadiana original ${ }^{48}$ e prossegue a

48 Na década de 1970, de auge da centralização estatal imposta pelos governos militares, as instituições encarregadas do desenvolvimento regional já haviam sido esvaziadas daqueles princípios federativos que nortearam a sua criação. O caso típico aqui é o da Sudene. Como observa Celso Furtado: a Sudene fora originalmente concebida como um instrumento "que deveria canalizar e expressar uma vontade política regional. Face às crescentes desigualdades entre Estados, o princípio federativo somente seria salvo se emergissem instâncias decisórias intermédias. A fórmula que se encontrou consistiu na adesão voluntária dos governadores da região a um órgão deliberativo destinado a gerar uma vontade política regional e a exercer essa vontade dentro do governo federal, no legislativo como no executivo. Não se tentava apenas de lidar com as questões específicas da região, mas também estar presente nas instâncias que definem a política global do país, a fim de que nenhuma decisão maior fosse tomada sem ter em conta seus efeitos na região economicamente mais débil. Na medida em que o Poder Executivo foi ocupando mais espaço no campo das decisões substantivas, o princípio federativo se foi diluindo. A votação do orçamento federal, que era expressão. maior. da vontade política a nação, perdeu grande parte de seu relevo, a partir do momento em que o executivo adotou a técnica da 'liberação de verbas' [...]. Não se pode desconhecer que o poder executivo, em particular no que respeita às instâncias que atuam no campo econômico-financeiro, está sob forte influência das regiões em que se concentra o poder econômico. A Sudene, na forma [...] concebida, deveria constituir-se em contra- 
prática da barganha pelas verbas "federais", com que tanto se deleitam os cientistas políticos estudiosos do malapportionment. Ora, nos marcos do federalismo, afiançado na Constituinte de 1986-88, a sobre-representação é explicada pela hiposuficiência, pois a região é (ou seria) pobre.

Mas de que região se está falando? Porque entre tantas novidades (e em consequência delas), eis que emergem diversos "Nordestes" dentro do Nordeste $^{49}$ : pólos de fruticultura irrigada para exportação, pólos de produção de insumos, pólos turísticos, pólos de produção e difusão de conhecimento que são referência internacional, surgidos sob a égide da transformação do "investimento em desenvolvimento" "crédito para o desenvolvimento" nos marcos da financeirização do capital. Nordestes "que deram certo" em meio aos "resquícios feudais", cuja formulação era grata a Josué de Castro. Seria esta uma constatação de imprevisíveis vitórias econômicas na batalha contra as adversidades e o fatalismo, ambos tão nordestinos?

Concordamos, com Francisco de Oliveira, que não deixa de ser novidade que "a questão nordestina é a de níveis de miséria produzidos pela própria expansão econômica. Bela e feia novidade" ${ }^{51}$. Concordamos, ainda, que é preciso desregionalizar o debate regional, a região, o Nordeste. Aposentar a sua função de "metro". Porque o Nordeste que restou, apartado daquele que "virou" Brasil e que investe e produz em São Paulo, é o Nordeste cuja minguada importância econômica circunscreve-o a beneficiário das transferências governamentais.

peso no âmbito do poder executivo, a essa influência. Carecendo de poder econômico, procurava o Nordeste valorizar o peso político que lhe advém de fatores históricos e da expressão demográfica. Contudo, esse fator político se anula, ou perverte, no quadro de um regime autoritário, que por definição é centralizador. Não é de admirar que a Sudene se haja descaracterizado a partir do momento em que se esvaziou a autonomia dos Estados e os governadores já não exerciam um mandato popular.” Acrescentaríamos que se substituiu o planejamento, e os planejadores, pela tecnocracia. Redemocratizado o País, o modelo de gestão da Sudene não seria revisto. FURTADO, Celso. A nova dependência: dívida externa e monetarismo. Rio de Janeiro: Paz e Terra, 1982.

49 Até onde sabemos a constatação, nesses termos, é da Profa. Tânia Bacelar, furtadiana da melhor cepa.

50 Explicado, à base das clivagens regionais, pela transformação do "modelo" pernambucano, cooperativo, em "modelo" cearense, competitivo.

51 OLIVEIRA, Francisco de. A metamorfose da arribaçã: fundo público e regulação autoritária na expansão econômica do Nordeste. In: Os direitos do antivalor: a economia política da hegemonia imperfeita. Petrópolis: Vozes, 1997· p.119. 